\title{
Effect of Wood-derived Charcoal Content on Properties of Wood Plastic Composites
}

\author{
Nadir Ayrilmis ${ }^{a *}$, Jin Heon Kwon ${ }^{b}$, Tae Hyung Han ${ }^{b}$, Ali Durmus ${ }^{c}$ \\ ${ }^{a}$ Department of Wood Mechanics and Technology, Forestry Faculty, Istanbul University, \\ Bahcekoy, Sariyer, 34473, Istanbul, Turkey \\ ${ }^{b}$ Department of Forest Biomaterials Engineering, College of Forest and Environmental Sciences, \\ Kangwon National University, 200-701 Chuncheon city, Republic of Korea \\ 'Department of Chemical Engineering, Faculty of Engineering, Istanbul University, \\ Avcilar, 34310, Istanbul, Turkey
}

Received: May 7, 2015; Revised: June 4, 2015

\begin{abstract}
The effect of wood-derived charcoal flour on the water resistance and mechanical properties of wood plastic composite (WPC) panels was investigated. The hot press molded WPC panels were produced from polypropylene (37 wt \%) with maleic anhydride-grafted polypropylene (MAPP, $3 \mathrm{wt} \%$ ) and different mixtures of wood flour and charcoal flour. The amount of charcoal flour was gradually increased up to $60 \mathrm{wt} \%$. The thickness swelling and water absorption of WPC panels considerably decreased with increasing charcoal flour content. The internal bond strength and bending properties of the WPC panels significantly improved with increasing charcoal flour content. This was mainly attributed to the high amount of pores and gaps in the charcoal flour. Melted polypropylene could get into the pores and gaps during the hot press molding, which lead to a better interfacial adhesion between polymer matrix and wood filler. The results showed that the charcoal flour could be partially substituted for the wood flour in the production of WPC panels having higher dimensional stability and internal bond strength.
\end{abstract}

Keywords: charcoal, polypropylene, wood, wood plastic composite

\section{Introduction}

Lignocellulosics are increasingly applied for the reinforcement in thermoplastics such as polypropylene and polyethylene due to wood's low density, good thermal insulation and mechanical properties, reduced tool wear, unlimited availability, low price, and problem-free disposal ${ }^{1}$. Wood flour is the most common lignocellulosic used in wood plastic composites (WPCs). It is a commercially available material sourced from industrial residues such as planer shavings, sawdust, and wood chips and ground to a consistent mesh size. WPC is stiffer, exhibits less creep, and is more dimensionally stable than unfilled plastic ${ }^{2}$. However, the inherent problems with wood such as moisture sorption and thickness swelling remain. Wood is a hydrophilic porous composite of cellulose, lignin, and hemicellulose polymers that are rich in functional groups such as hydroxyls, which readily interact with water molecules by hydrogen bonding. The hydroxyl groups form new hydrogen bonds with water molecules, which induce the water absorption, fiber swelling, and creation of micro-cracks in the specimens. This results in debonding fibers and degradation of interface of fiber-matrix. For this reason, WPCs have potential to take up water under humid conditions due to the presence of numerous hydroxyl groups.

Charcoal is the chief product of the pyrolysis of wood. It is not pure carbon, but a complex combination of primary carbon plus a secondary deposit of $\operatorname{tar}^{3}$. The wood particles

*e-mail: nadiray@istanbul.edu.tr can be transformed to wood charcoal at a high temperature under nitrogen atmosphere. Its specific gravity varies depending on the method of preparation. It has a specific gravity of 1.5 to 1.9 . Wood charcoal is porous structure and can adsorb liquids and gases on its porous surface. Therefore, it is used in water filters, gas masks and antigastric tablets for people suffering from indigestion ${ }^{4}$.

In order to improve the dimensional stability and mechanical properties of WPC, various approaches have been carried out $^{5-10}$. Some of them are concentrated on the modification of the wood, such as acetylation, silane treatment, thermal treatment, and treatment with sodium hydroxide ${ }^{3-5}$. Furthermore, the incorporation of nanoparticles into the WPC as reinforcing filler is another method for improving the overall properties of WPC, such as silica nanopowder, montmorillonite, and hexagonal boron nitride ${ }^{8-10}$. However, these methods have their own weaknesses, such as complicated processing processes, high-cost, and easy aggregation of nanoparticles. The porous nature of charcoal might be able to stronger interface between wood filler and polymer matrix, because polymer chains could get into the holes of the charcoal as the polymer has good liquidity ${ }^{11}$. In addition to its porous structure, charcoal has hydrophobic properties, which may make it an important factor in WPC. Wood-derived charcoal could play an important role in the manufacture of WPCs as reinforcing filler and may be one of the most efficient uses of the charcoal. The effect of different lignocellulosic materials on the dimensional stability and mechanical properties of 
WPCs has been studied by many researchers, but the use of charcoal as a thermoplastic filler has not been extensively investigated. The aim of this study was to investigate the effect of wood-derived charcoal flour on the dimensional stability and mechanical properties of WPC.

\section{Material and Methods}

\subsection{Materials}

A mixture of two charcoal species, Quercus mongolica Fisch (20 wt \%) and Quercus variabilis Blume (80 wt\%), was supplied by a commercial charcoal producer in South Korea. The dry charcoal was crushed with a blade mixer and sieved with sieve ( 80 mesh) into an appropriate particle size. The screened charcoal flour was stored in a plastic bag.

The wood particles used in the face layers of particleboard were supplied from a commercial particleboard plant in South Korea. The moisture content of wood particles prior to the manufacture of the WPC panels was found to be $4-6 \%$ based on the oven-dry weight of the wood particles. The wood particles were hammer milled to obtain wood flour (60 mesh). The wood flour and charcoal flour were dried in a laboratory oven at $100{ }^{\circ} \mathrm{C}$ for $24 \mathrm{~h}$ to reach $0-1 \%$ moisture content and then stored in sealed plastic bags until blending with polypropylene.

Polypropylene flour $\left(\mathrm{MFI} / 230^{\circ} \mathrm{C} / 2.16 \mathrm{~kg}=35 \mathrm{~g} / 10 \mathrm{~min}\right.$, density: $0.90 \mathrm{~g} / \mathrm{cm}^{3}$ ) produced by Lotte Chemical Corporation in South Korea, was used as the polymeric material. The compatibilizing agent, maleic anhydride-grafted polypropylene (MAPP) $\left(\mathrm{MFI} / 190^{\circ} \mathrm{C}, 2.16 \mathrm{~kg}=\right.$ more than $100 \mathrm{~g} / 10 \mathrm{~min}$, density: $0.36 \mathrm{~g} / \mathrm{cm}^{3}$ ) flour, was supplied by Lotte Chemical Corporation in South Korea.

\subsection{Production of experimental WPC panels}

After mixing the wood flour, charcoal flour, polypropylene and MAPP flour, the mixture was placed in a rotary drum blender. Following the blending treatment for $5 \mathrm{~min}$, the mixture was weighed and formed on an aluminum caul plate, using a $290 \mathrm{~mm} \times 290 \mathrm{~mm}$ forming frame. A steel frame was used to prevent a lateral yielding of the dry-blend mixture during the hot pressing. Wax paper was used to avoid direct contact of the polypropylene flour with the metal platens of the hot-press. To reduce the mat height and to densify the mats, they were subjected to a cold-press. The mats were hot pressed for $8 \mathrm{~min}$ under $5.5 \mathrm{MPa}$ at $190^{\circ} \mathrm{C}$ in a one-step process. At the end of the hot pressing cycle, the panel was immediately moved from the hot press into a press at room temperature for cooling. $10 \mathrm{~mm}$ thick panels were then trimmed to a final size of $280 \mathrm{~mm} \times 280 \mathrm{~mm}$. A total of 14 experimental WPC panels, 2 panels for each formulation of WPC panel, were manufactured (Table 1). The specimens were conditioned to constant mass at a temperature of $23^{\circ} \mathrm{C}$ and a relative humidity of $50 \%$ according to ISO $291^{12}$.

\subsection{Determination of dimensional stability of samples}

Thickness swelling (TS) and water absorption (WA) tests were carried out according to $\mathrm{EN} 317^{13}$. Ten replicate specimens, $50 \mathrm{~mm} \times 50 \mathrm{~mm} \times 10 \mathrm{~mm}$, from each type of WPC were used for the TS and WA properties. At the end of 1-day, 7 days, and 30 days of submersion, the WPC specimens were taken out from the water and all surface water was removed with a clean dry cloth. The specimens were weighed to the nearest $0.01 \mathrm{~g}$ and measured to the nearest $0.001 \mathrm{~mm}$ immediately. The specimen thickness was determined by taking a measurement at a specific location, the diagonal crosspoint, on the specimen. The densities of specimens were evaluated according to the test method specified in EN $323^{14}$.

\subsection{Determination of mechanical properties of samples}

The bending strength (MOR) and modulus of elasticity (MOE) of the specimens were performed according to EN $310^{15}$. A total of 10 replicate specimens with dimensions of $250 \mathrm{~mm} \times 50 \mathrm{~mm} \times 10 \mathrm{~mm}$ were tested for each type of particleboard. The bending tests were conducted in accordance with the third point loading method at a span-to-depth ratio of $20: 1$. The crosshead speed was adjusted so that the failure would occur within an average of $60 \mathrm{~s} \pm 10$. The specimens were tested on Instron testing machine (Model: 4482) equipped with a load cell with a capacity of $10 \mathrm{kN}$. Internal bond (IB) tests were conducted on the specimens cut from the experimental WPC panels according to EN $319^{16}$. Ten specimens with dimensions of $50 \mathrm{~mm}$ x $50 \mathrm{~mm}$ x 10 $\mathrm{mm}$ from each type of WPC panel were used to determine the IB strength.

Table 1. Experimental design.

\begin{tabular}{ccccc}
\hline \multirow{2}{*}{ WPC type } & \multicolumn{3}{c}{ WPC composition } \\
\cline { 2 - 5 } & Wood flour & Charcoal flour & Polypropylene flour & Coupling agent(MAPP) flour \\
\cline { 2 - 5 } (wt $\%)$ & $(\mathbf{w t} \%)$ & 37 & 3 \\
A & 60 & 0 & 37 & 3 \\
B & 50 & 10 & 37 & 3 \\
C & 40 & 20 & 37 & 3 \\
D & 30 & 30 & 37 & 3 \\
E & 20 & 40 & 37 \\
F & 10 & 50 & 37 \\
G & 0 & 60 & 37 \\
\hline
\end{tabular}




\subsection{Interfacial morphological analysis}

Micro-structural features and morphological properties of charcoal flour and composites were investigated by a field emission scanning electron microscope (FE-SEM, FEI Quanta FEG 450) operated at $30 \mathrm{kV}$. SEM analysis was performed on the cryo-fractured cross-sections of rectangular bar-shaped specimens of composite samples into liquid nitrogen in the electron microscope after a proper sample preparation, sputter coating with gold.

\subsection{Statistical analysis}

An analysis of variance, ANOVA, was conducted $(p<0.01)$ to evaluate the effect of the charcoal content on the dimensional stability and mechanical properties of the WPCs. Significant differences between the average values of types of the WPCs were determined using Duncan's multiple range test.

\section{Results and Discussion}

\subsection{Morphological analysis of samples by SEM}

The SEM images of charcoal flour ( $a$ and $b$ ) and the WPC sample Type A (c and d), and charcoal filled polypropylene composite sample Type $\mathrm{G}$ (e and $\mathrm{f}$ ), taken at different magnifications are presented in Figure 1. As obviously seen in Figure 1a and 1b, the charcoal flour consists of highly porous particles with the average size of 80-100 $\mu \mathrm{m}$. The average size of eliptic pores can be estimated in the range of $5-15 \mu \mathrm{m}$. The SEM images of composite type A illustrated that the wood fibers were successfully and homogenously dispersed into the polymer matrix. In these figures, a strong interfacial adhesion between the wood fibers and polymer matrix can also be clearly seen. Figure 1e and $1 \mathrm{f}$ exemplify the microstructure of sample G. In the micro-structural characterization study of sample $\mathrm{G}$, two distinctive domains were observed. As seen in Figure 1e, it was found that the porous charcool particles formed irregular stacks possibly due to the collapsing and/or destructuring of porous structure as a result of intensive mixing and shear forces during melt processing. But in some domains of the composite sample, it was also seen that the pores of charcoal particles were filled with the matrix polymer as shown in Figure 1f. Such kind of melt-penetrated structure were previously reported for the polymer/charcoal composites ${ }^{17-19}$. In both domains, the lack of huge gaps or voids at interface implies that the interfacial interactions between the charcoal surface and polymer phase are sufficiently strong.

\subsection{Dimensional stability}

The TS and WA values of WPCs with and without charcoal flour are presented in Table 2. The dimensional stability of the specimens was significanty improved by increasing charchoal flour content. The composites made with charcoal flour showed significantly higher $(\mathrm{p}<0.01)$ water resistance than the composites made with the wood flour (Table 2). The TS and WA values (30 days) of polypropylene composites filled with $60 \mathrm{wt} \%$ wood flour were found to be $6.54 \%$ and $21.20 \%$ while these properties were found to be $3.66 \%$ and $15.37 \%$ for the polypropylene composites filled with $60 \mathrm{wt} \%$ charcoal flour, respectively. The improvement in the dimensional stability can be explained by the fact that the charcoal contains many pores and gaps in its structure. The wood-derived charcoal has small holes lengthwise and crosswise and its inner surface is about $50 \mathrm{~m}^{2} / \mathrm{g}^{[20]}$. The results of TS and WA tests suggested that the pores and gaps in the structure of charcoal were filled by melted polypropylene. This was confirmed by the SEM image (Figure 1f).
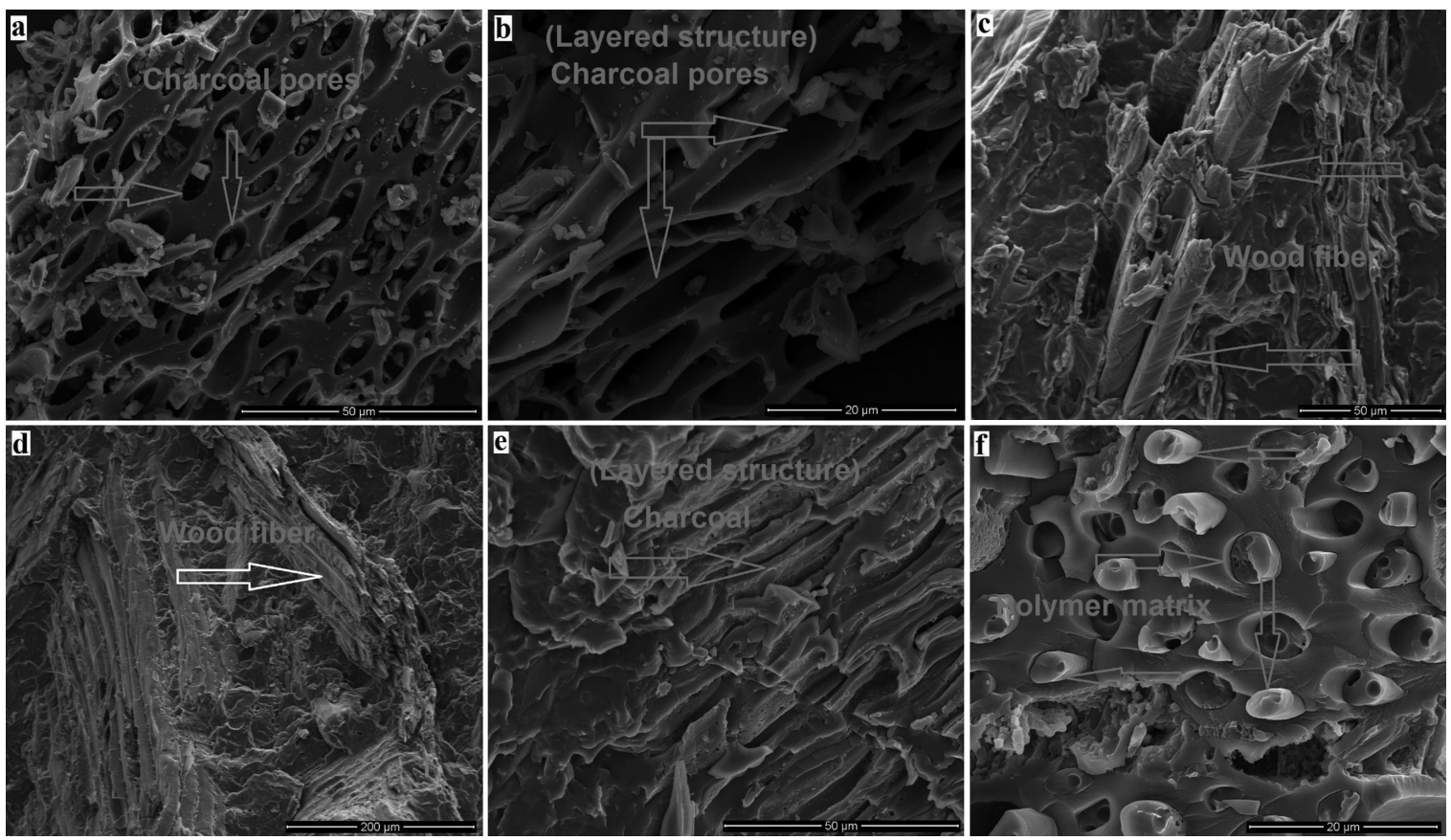

Figure 1. SEM images of charcoal flour and fracture surfaces of wood flour or charcoal flour filled polypropylene composites. 
The surface of charcoal has hydrophobic sites consisting of carbon layers, apart from wood surface ${ }^{21}$. The lower TS of the WPC panels containing the charcoal flour was also attributed to the hydrophobic sites on the charcoal surface.

WPCs absorb water by three different boundaries, i.e. at the lumen and cell wall of wood filler and at the voids between wood filler and polymer matrix. The presence of voids and spaces plays an important role in the degree of WA because water is easily absorbed by these voids. The WPCs without the charcoal flour absorbed more water than the WPCs containing charcoal, because of the increased number of voids between the large amount of wood flour and polypropylene. The increment in the amount of the charcoal flour considerably decreased the TS and WA values. 24-h TS values of all WPC panel types met maximum requirement (10\%) for general purpose MDF boards (EN 622-5, type H) for use in humid conditions. In addition, the TS and WA values of the WPCs containing the charcoal flour were lower than those of WPCs containing thermally treated wood fibers ${ }^{6}$.

\subsection{Mechanical properties}

The incorporation of charcoal flour into the WPC significantly improved the bending properties of WPCs. The average MOR and MOE value of $60 \mathrm{wt} \%$ wood flour filled polypropylene composites (Type A) were found to be $22.4 \mathrm{~N} / \mathrm{mm}^{2}$ and $2426 \mathrm{~N} / \mathrm{mm}^{2}$ while they were found to be $28.2 \mathrm{~N} / \mathrm{mm}^{2}$ and $3145 \mathrm{~N} / \mathrm{mm}^{2}$ for $60 \mathrm{wt} \%$ charcoal flour filled polypropylene composites (Type G), respectively. Significant differences $(\mathrm{p}<0.01)$ among the WPC types for the MOR and MOE values are presented in Table 3 as letters. The IB strength of the WPCs signficantly increased with increasing charcoal flour content. The IB strength of the WPC without charcoal flour was $1.15 \mathrm{MPa}$ while it was found to be $1.88 \mathrm{MPa}$ for the WPCs with $60 \mathrm{wt} \%$ charcoal flour. The improvement in the IB strength clearly showed that the interfacial adhesion between the polymer matrix and wood filler was improved by adding the charcoal flour into the WPC. The improvement in the bending properties and internal bond performance of WPC panels were not significant as the amount of charcoal flour increased from 50 to $60 \mathrm{wt} \%$. The MOR, MOE, and IB values of WPC panel containing the charcoal flour above $30 \mathrm{wt} \%$ met MDF $\left(26 \mathrm{~N} / \mathrm{mm}^{2}\right.$ and $2500 \mathrm{~N} / \mathrm{mm}^{2}$, and $0.80 \mathrm{~N} / \mathrm{mm}^{2}$ ) minimum requirements of EN 622-522. In a previous study, Ayrilmis $\&$ Jarusombuti ${ }^{23}$ reported that the MOR and MOE of flat pressed WPC panels made from $60 \mathrm{wt} \%$ wood fibers and $37 \mathrm{wt} \%$ polypropylene with MAPP (3 wt $\%$ ) were $26.2 \mathrm{MPa}$ and $2978 \mathrm{MPa}$, respectively.

Positive effect of the charcoal on the mechanical properties of WPC panel was mainly attributed to the fact that charcoal contains many pores and gaps in its structure and polypropylene chains get into the pores and gaps. This leads to a better interfacial adhesion between the polymer matrix and wood charcoal filler. The polypropylene ( $35 \mathrm{~g} / 10 \mathrm{~min})$ used in this study had a good liquidity. Therefore, the melted polymer could fill into the pores and gaps of charcoal and results in better interfacial adhesion between the polymer matrix and charcoal (Figure 1f). The improvement in the

Table 2. Density and water resistance of WPC panels with and without charcoal flour.

\begin{tabular}{|c|c|c|c|c|c|c|c|}
\hline \multirow{3}{*}{$\begin{array}{l}\text { WPC } \\
\text { type }^{1}\end{array}$} & \multicolumn{7}{|c|}{ Water resistance } \\
\hline & \multirow{2}{*}{$\begin{array}{l}\text { Density } \\
\left(\mathrm{g} / \mathrm{cm}^{3}\right)\end{array}$} & \multicolumn{3}{|c|}{ Water absorption (\%) } & \multicolumn{3}{|c|}{ Thickness swelling (\%) } \\
\hline & & 1 day & 7 days & 30 days & 1 day & 7 days & 30 days \\
\hline $\mathrm{A}$ & $0.84(0.04)$ & $3.22(0.19) \mathrm{a}^{2}$ & $10.12(0.62) \mathrm{a}$ & $21.20(1.26) \mathrm{a}$ & $2.46(0.21) \mathrm{a}$ & $4.23(0.33) \mathrm{a}$ & $6.54(0.44) \mathrm{a}$ \\
\hline B & $0.82(0.05)$ & $3.06(0.23) \mathrm{a}$ & $9.31(0.49) \mathrm{ab}$ & $20.53(1.19) \mathrm{ab}$ & $2.25(0.17) a b$ & $3.85(0.29) a b$ & $5.44(0.38) a b$ \\
\hline $\mathrm{C}$ & $0.84(0.06)$ & $2.81(0.15) b$ & $9.18(0.54) \mathrm{abc}$ & $19.26(1.23) \mathrm{bc}$ & $1.98(0.15) b c$ & $3.52(0.33) a b$ & $5.13(0.41) b c$ \\
\hline $\mathrm{D}$ & $0.83(0.09)$ & $2.78(0.13) b d$ & $9.02(0.49) b c$ & $18.68(1.16) \mathrm{c}$ & $1.91(0.14) b c$ & $3.24(0.26) b c$ & $4.88(0.33) b c$ \\
\hline $\mathrm{E}$ & $0.81(0.04)$ & $2.64(0.14)$ bde & $8.85(0.55)$ bcd & $18.11(1.06) \mathrm{c}$ & $1.86(0.18) \mathrm{cd}$ & $3.18(0.21) b c$ & $4.66(0.40) b c$ \\
\hline $\mathrm{F}$ & $0.82(0.07)$ & $2.23(0.11) \mathrm{de}$ & $8.23(0.48) \mathrm{cd}$ & $16.63(1.21) \mathrm{d}$ & $1.70(0.13) \mathrm{cd}$ & $2.79(0.24) \mathrm{c}$ & $4.12(0.32) \mathrm{cd}$ \\
\hline G & $0.83(0.06)$ & $2.11(0.14) \mathrm{e}$ & $7.89(0.33) \mathrm{d}$ & $15.37(0.95) \mathrm{e}$ & $1.51(0.15) \mathrm{d}$ & $2.61(0.19) \mathrm{c}$ & $3.66(0.29) \mathrm{d}$ \\
\hline
\end{tabular}

${ }^{1}$ See Table 1 for WPC formulation. ${ }^{2}$ Groups with same letters in column indicate that there is no statistical difference $(\mathrm{p}<0.01)$ between the specimens according to Duncan's multiply range test. The values in the parentheses are standard deviations.

Table 3. Mechanical properties of WPC panels with and without charcoal flour.

\begin{tabular}{cccc}
\hline & \multicolumn{3}{c}{ Mechanical properties } \\
\cline { 2 - 4 } WPC type $^{1}$ & Bending strength & Bending modulus & Internal bond strength \\
\cline { 2 - 4 } & (MPa) & $($ MPa $)$ & (MPa) \\
\hline A & $22.4(0.9) \mathrm{a}^{2}$ & $2426(108) \mathrm{a}$ & $1.15(0.10) \mathrm{a}$ \\
$\mathrm{B}$ & $23.9(1.6) \mathrm{b}$ & $2581(96) \mathrm{b}$ & $1.32(0.13) \mathrm{b}$ \\
C & $24.4(1.1) \mathrm{b}$ & $2740(117) \mathrm{c}$ & $1.50(0.16) \mathrm{c}$ \\
$\mathrm{D}$ & $26.3(1.2) \mathrm{c}$ & $2815(132) \mathrm{cd}$ & $1.63(0.14) \mathrm{d}$ \\
E & $27.5(1.7) \mathrm{d}$ & $2886(121) \mathrm{d}$ & $1.75(0.12) \mathrm{e}$ \\
F & $28.8(1.3) \mathrm{e}$ & $3078(154) \mathrm{e}$ & $1.86(0.17) \mathrm{f}$ \\
G & $28.2(2.0) \mathrm{e}$ & $3145(133) \mathrm{e}$ & $1.88(0.14) \mathrm{f}$ \\
\hline
\end{tabular}

${ }^{1}$ See Table 1 for WPC formulation. ${ }^{2}$ Groups with same letters in column indicate that there is no statistical difference (p $\left.<0.01\right)$ between the specimens according to Duncan's multiply range test. The values in the parentheses are standard deviations. 
mechanical properties of WPCs containing charcoal flour could be also attributed to the homogeneous dispersion of charcoal flour due to its mesh size ( 80 mesh). A similar result was found by Li et. $\mathrm{al}^{11}$. They reported that the holes in bamboo charcoal could be able to stronger interface between filler and polymer matrix.

The improvement in the interfacial adhesion results in more restriction to deformation capacity of the polymer matrix in the elastic zone and increasing modulus. The stress transfer from the polymer matrix to the wood filler increased with increasing charcoal flour content due to the decrease in the micropores and gaps between the polymer matrix and wood flour. You $\& \mathrm{Li}^{24}$ reported that the incorporation of bamboo charcoal flour into the polyethylene improved the elastic recovery and decreased the recovered strain remarkably. Carbon-based fillers act as a solid lubricant reducing the coefficient of friction ${ }^{25}$, while also potentially improving other mechanical properties of the thermoplastic composites $^{26,27}$.

\section{Conclusions}

The results showed that the composites made with charcoal flour showed better water resistance and mechanical properties compared to the composites made with wood flour

\section{References}

1. Kaymakci A, Ayrilmis N, Ozdemir F and Gulec T. Utilization of sunflower stalk in manufacture of thermoplastic composite. Journal of Polymer and Environment. 2013; 19(4):918-925.

2. Clemons C. Wood-plastic composites in the United States: the interfacing of two industries. Forest Products Journal. 2002; 52(6):10-18.

3. Ishihara S. Carbon composites. In: Salamone JC. Concise polymeric materials encyclopedia. Boca Raton: CRC Press; 1999. p. 956-968.

4. Zhao RS, Wang X, Yuan JP and Lin JM. Investigation of feasibility of bamboo charcoal as solid-phase extraction adsorbent for the enrichment and determination of four phthalate esters in environmental water samples. Journal of Chromatography. A. 2008; 1183(1-2):15-20. http://dx.doi. org/10.1016/j.chroma.2008.01.021. PMid:18243227.

5. Lee SH and Wang S. Biodegradable polymers/bamboo fiber biocomposite with bio-based coupling agent. Composites. Part A, Applied Science and Manufacturing. 2006; 37(1):80-91. http://dx.doi.org/10.1016/j.compositesa.2005.04.015.

6. Ayrilmis N, Jarusombuti S, Fueangvivat V and Bauchongkol P. Effect of thermal-treatment of wood fibres on properties of flat-pressed wood plastic composites. Polymer Degradation \& Stability. 2011; 96(5):818-822. http://dx.doi.org/10.1016/j. polymdegradstab.2011.02.005.

7. Ichazo MN, Albano C, Gonzalez J, Perera R and Candal MV. polypropylene wood flour composites treatments and properties. Composite Structures. 2001; 54(2-3):207-214. http://dx.doi. org/10.1016/S0263-8223(01)00089-7.

8. Deka BK and Maji TK. Effect of silica nanoflour on the properties of wood flour/polymer composite. Polymer Engineering and Science. 2012; 52(7):1516-1523. http://dx.doi.org/10.1002/ pen.23097. or wood/charcoal flour. The improvement in the mechanical properties was explained by the fact that the charcoal flour constrained mobility of the chains of the polymeric matrix. The incorporation of charcoal flour into the WPC improved the elastic recovery and decreased the recovered strain remarkably. Better bending properties and internal bond strength could be attributed to the homogeneous dispersion of charcoal flour in the WPC. Charcoal contains many pores and gaps in its structure. Polypropylene chains get into the pores and gaps, which lead to a better interfacial adhesion between polymer matrix and wood filler. The increase in the amount of the charcoal flour decreased the TS and WA of WPC panels because of the decreased number of voids between the wood flour and polypropylene. The charcoal flour acted as a solid lubricant reducing the coefficient of friction. The improvement in the mechanical properties of WPC panels was not significant as the amount of charcoal flour increased from 50 to $60 \mathrm{wt} \%$.

\section{Acknowledgements}

This study was supported by 2015 Research Grant from Kangwon National University and with the support of the MSIP (Ministry of Science, Ict \& Future Planning) Republic of Korea.

9. Devi RR and Maji TK. Preparation and characterization of wood/styreneacrylonitrile copolymer/MMT nanocomposite. Journal of Applied Polymer Science. 2011; 122(3):2099-2109. http://dx.doi.org/10.1002/app.34291.

10. Ayrilmis N, Dundar T, Kaymakci A, Ozdemir F and Kwon JH. Mechanical and thermal properties of wood-plastic composites reinforced with hexagonal boron nitride. Polymer Composites. 2014; 35(1):194-200. http://dx.doi.org/10.1002/pc.22650.

11. Li X, Lei B, Lin Z, Huang L, Tan S and Cai X. The utilization of bamboo charcoal enhances wood plastic composites with excellent mechanical and thermal properties. Materials \& Design. 2014; 53(1):419-424. http://dx.doi.org/10.1016/j. matdes.2013.07.028.

12. International Organization for Standardization - ISO. ISO 291: plastics: standard atmospheres for conditioning and testing. Geneva: ISO; 2008.

13. European Committee for Standardization - CEN. EN 317: particleboards and fiberboards: determination of swelling in thickness after immersion in water. Brussel: CEN; 1993.

14. European Committee for Standardization - CEN. EN 323: wood-based panels: determination of density. Brussel: CEN; 1993.

15. European Committee for Standardization - CEN. EN 310: determination of modulus of elasticity in bending and bending strength. Brussel: CEN; 1993.

16. European Committee for Standardization - CEN. EN 319: particleboards and fibreboards: determination of tensile strength perpendicular to the plane of the board. Brussel: CEN; 1993.

17. Kumar A, Gupta A, Sharma KV, Nasir M and Khan TA. Influence of activated charcoal as filler on the properties of wood composites. International Journal of Adhesion and Adhesives. 2013; 46(10):34-39. http://dx.doi.org/10.1016/j. ijadhadh.2013.05.017.

18. Li S and Li D. Carbon fiber reinforcedhighly filled charcoalpowder/ ultrahigh molecular weightpolyethylenecomposites. Materials 
Letters. 2014; 134(11):99-102. http://dx.doi.org/10.1016/j. matlet.2014.07.081.

19. Li S and Li D. Electrically conductive charcoal powder/ ultrahigh molecular weight polyethylene composites. Materials Letters. 2014; 137(12):409-412. http://dx.doi.org/10.1016/j. matlet.2014.09.022.

20. Lou CW, Lin CW, Lei CH, Su KH, Hsu CH, Liu ZH, et al. PET/ $\mathrm{PP}$ blend with bamboo charcoal to produce functional composites. Journal of Materials Processing Technology. 2007; 192-193:428433. http://dx.doi.org/10.1016/j.jmatprotec.2007.04.018.

21. Dalahmeh S. Bark and charcoal filters for greywater treatment. Uppsala Sweden: Swedish University of Agricultural Sciences; 2013. 75 p.

22. European Committee for Standardization - CEN. EN 622-5: fibreboards: specifications: requirements for dry process boards (MDF). Brussel: CEN; 2009.

23. Ayrilmis N and Jarusombuti S. Flat-pressed wood plastic composite as an alternative to conventional wood-based panels.
Journal of Composite Materials. 2011; 45(1):103-112. http:// dx.doi.org/10.1177/0021998310371546.

24. You Z and Li D. Highly filled bamboo charcoal powder reinforced ultra-high molecular weight polyethylene. Materials Letters. 2014; 122(5):121-124. http://dx.doi.org/10.1016/j. matlet.2014.01.010.

25. Sui G, Zhong WH, Ren X, Wang XQ and Yang XP. Structure, mechanical properties and friction behavior of UHMWPE/ HDPE/carbon nanofibers. Materials Chemistry and Physics. 2009; 115(1):404-412. http://dx.doi.org/10.1016/j. matchemphys.2008.12.016.

26. Galetz MC, Bla $\beta$ T, Ruckdäschel H, Sandler JKW, Altstädt V and Glatzel U. Carbon nanofibre-reinforced ultrahigh molecular weight polyethylene for tribological applications. Journal of Applied Polymer Science. 2007; 104(6):4173-4181. http:// dx.doi.org/10.1002/app.26058.

27. Werner P, Altstadt V, Jaskulka R, Jacobs O, Sandler JKW, Shaffer MSP, et al. Tribological behaviour of carbon-nanofibre-reinforced poly (ether ether ketone). Wear. 2004; 257(9-10):1006-1014. http://dx.doi.org/10.1016/j.wear.2004.07.010. 